\title{
On College Students' impulsive consumption psychology-the influence of trait power and money priming
}

\author{
Yuan Zhuang \\ School of Humanities Southeast University, Nanjing, Jiangsu, 210008, China \\ Email: 18706569729@163.com
}

\begin{abstract}
Two experiments were conducted to explore the effects of trait power and money priming on College Students' impulse buying. In both experiments, Sense of Power Scale (SPS) was used to select subjects with high and low trait power to participate in the experiment; in Experiment 1, scrambled-words task was used to activate the concept of money; in Experiment 2, the method of mindset priming was used to activate the amount of money. The results show that: (1) After the concept of money is activated, individuals with low trait power have higher impulse purchase intention than those with high trait power, regardless of whether they are rich or poor; however, there is no significant difference between high and low power groups in no money concept priming group. (2) No matter whether the level of individual's trait power is high or low, compared with the condition of lack of money, individuals have higher impulse purchase intention under the condition of money abundance.
\end{abstract}

Keywords: College Students' psychology, Trait power, Money priming, Impulse Purchase

CLC No.: B849

\section{Introduction}

According to reports, $20 \%$ of grocery purchases are caused by impulse. The impulse buying behavior that consumers make because of the impulse or irrationality (rook \& Fisher, 1995; Shukla, Banerjee, \& adidam, 2013). According to the survey of China Youth Research, the average annual per capita expenditure of college students is 8435.73 yuan. College students are an important part of the youth group and the main consumer group (Li linyao, Zhang Mian, 2013). As a special consumer group in the society, contemporary college students' consumption concepts and habits directly or indirectly affect the formation and development of their three outlooks, and then affect the future lifestyle and even the cultivation of life attitude and good social moral behavior. Therefore, it is very important to study the consumption psychology of college students.

It is found that the main influencing factors of College Students' impulsive buying behavior are external factors and personal factors, among which the external factors include situational factors and market incentives (Dholakia, 2000; abdolv, hanzaee, rahnam, \& khoshpanje, 2011); the factors of college students themselves include personal characteristics, economic situation, emotion, sense of power, etc. Among them, the influence of sense of power and money on impulse purchase is a hot topic in the field of College Students' purchase decision-making. It is found that different sense of power can affect consumers' cognitive style and generate specific behavioral tendencies, including impulse buying control and brand switching behavior (Smith \& trope, 2006; Kim et al., 2017; Jiang Hongyan, Liu BANGSHUN, sun Puzhen, 2018). However, the direction of the influence of sense of power on impulse buying behavior has been controversial. Shiv, Baba and fedorikhin (1999) found that when resources are insufficient, individuals are more dependent on perceptual decision-making. When the resources are sufficient, the abundant cognitive resources

Copyright (C) 2020 Yuan Zhuang

doi: 10.18282/le.v9i5.1255

This is an open-access article distributed under the terms of the Creative Commons Attribution Non-Commercial License

(http://creativecommons.org/licenses/by-nc/4.0/), which permits unrestricted non-commercial use, distribution, and reproduction in any medium, provided the original work is properly cited. 
make individuals rely more on rationality and inference to make choices (Vohs \& Faber, 2007). College students with sufficient resources are more likely to control impulsive purchase desire, so those with higher sense of power with more resources tend to have less impulsive buying behaviors than those with low sense of power. In addition, some studies suggest that high sense of power enhances self-monitoring in order to realize long-term interests (Baumeister et al., 1998; McCullough \& Willoughby, 2009). People with low sense of power are easy to be influenced by immediate pleasure because of their shortsightedness, which leads to the increase of impulse buying behavior. However, some studies suggest that high-power people can flexibly control their own resources (Keltner et al., 2003; Van \& Pope, 2006), and are more positive and confident in the future (Keltner et al., 2003), so they are more likely to choose pleasure in their purchase behavior. In order to avoid risk, individuals with low trait power tend to restrain impulse buying behavior due to lack of resources. Then, how does the sense of power affect college students' impulse buying? This is the first question to be explored in this study.

For consumers, money is not only a sign of price, but also an implicit potential variable influencing individual thinking and choice (Li Aimei, Luo Ying, Li Bin, 2016). When consumers enter the shopping mall, the price and discount information everywhere, the luxury decoration in shops or the gold products placed in the counter will change people's psychology. Because the income of college students comes from their parents and their disposable amount is limited, the concept of money is more likely to be aroused in this group. Studies on money priming have found that money priming makes individuals' thinking patterns change and tend to maximize their income (Zhou \& Pham, 2004). When individuals prime the concept of money, they tend to use rational thinking to solve problems, value the safety, functionality and effectiveness of products, but ignore the emotional benefits of products (Mogilner \& Aaker, 2009). In addition, the study found that priming the sense of money abundance can stimulate the individual's high level of explanation, and then increase the individual's sense of social distance (Hansen, kutzner, \& W ü NKE, 2013), making individuals think that external factors can be controlled. Moreover, they are less affected by external evaluation, so they are more likely to have unique consumption, that is, they tend to buy unique and distinctive goods (Tian, Bearden, \& hunter, 2001). On the contrary, Hansen et al. (2013) confirmed that the priming of sense of lack of money will reduce the level of interpretation of thinking, and individuals pay attention to the surface features of goods, and their selfcontrol will be weakened. Therefore, individuals can compensate for deprivation by buying luxury goods, which leads to compensatory consumption (trope \& Liberman, 2003; cutright, Bettman, \& Fitzsimons, 2013).

Studies have found that individuals with different sense of power have different attitudes towards money. Some studies have found that individuals with low sense of power secrete more saliva in front of money than those with high sense of power (Gal, 2012), and have a stronger desire for money reward. High sense of power significantly increases consumers' propensity to monitor and save money (garbinsky, klesse, \& Aaker, 2014; garbinsky, klesse, \& Huang, 2016). So when college students with different sense of power are faced with money priming, how will their impulse buying behavior be affected? This is the second question to be discussed in this study.

Therefore, this study will explore the impulsive buying behavior of college students with different sense of power in different money situations. The sense of power can be divided into special power sense and state power sense. The trait power refers to the stable personal characteristics, which is reflected in the long-term perception of whether or not the individual has power; the state power sense is the sense of power temporarily stimulated by priming (Yang Wenqi, Li Qiang, Guo Mingyang, fan Qian, he Yili, 2017). In daily life, the influence of trait power is more common than that of state power induced by priming stimulus, so this study only chooses trait power to study. Experiment 1 explored the effects of trait power and money concept priming on College Students' impulse purchase intention, and Experiment 2 explored the influence of trait power and money quantity priming on impulsive purchase intention. According to the situational focus theory of power, high-power people are more flexible and selective in cognitive processing, and are more likely to identify the needs of the situation and relevant information, so as to selectively process relevant information and ignore irrelevant information. However, low-power people have lower selective attention and cognitive flexibility, so high-power people show more consistent attitude and behavior than low-power people (guinote, 2007). Therefore, we speculate that because college students with high sense of power are more consistent with the situation, they are less likely to have impulsive buying tendency after money priming than those with low sense of power; 
However, college students with low sense of power want to make up for the lack of power by purchasing goods related to power (Rucker \& Galinsky, 2008), and they are more likely to have impulse buying tendency after the lack of money primings.

\section{Experiment 1}

\subsection{Method}

\subsubsection{Subjects}

A total of 198 college students were randomly selected. First, they took the trait power test. After ranking according to the total score, 108 subjects with the top $27 \%$ and the last $27 \%$ of the total score were selected to participate in the impulsive purchase decision-making experiment. There were 58 males and 50 females with an average age of 20 years.

\subsubsection{Experimental tasks and materials}

(1) Sense of power scale (SPS)

The scale was developed by Anderson, John and Keltner (2012). It includes 8 items, such as "in my relationship with others, I can make others listen to me". From "5" to "5", it was not consistent with the scale. In this study, the alpha coefficient of the scale was 0.78 .

(2) Scrambled-words task

The money priming and neutral priming tests in Duan Yi's (2014) were adapted from the task priming materials used by Vohs et al. (2006). The material contains 20 word groups, including 5 out of order words. The subjects need to form a meaningful sentence with 4 words. Different priming materials can make the subjects produce different conceptual mental states. Many words in the money concept priming group, such as loans and wealth, were related to money, while those in the neutral control group, such as boxes and plants, were not directly related to money.

(3) Impulse buying decision test

Using the research paradigm designed by rook and Fisher (1995), this paper presents the subjects with a practical product they planned to buy in the context of impulse purchase decision, but sees another attractive hedonic product at the same time, which needs to solve the contradiction of alternative choice. The subjects were asked to complete the 7-point scale compiled by wa Yu (2014), which contained 4 items, such as "I am very likely to buy the product", "I am eager to buy the product", etc. On the 7-point scale, participants estimated the level of each item's description in accordance with the actual situation (from "very inconsistent" to "very consistent", from "1" to "7"). In this study, the alpha coefficient of the scale was 0.88 .

(4) Positive and Negative Affect Schedule (PANAS)

The scale contains 20 items, positive emotions are detected by 10 items, such as "interested" and "powerful"; negative emotions are detected by 10 items, such as "restless" and "upset". On the 5-point scale, participants estimated the level of each item's description in accordance with the actual situation (from "almost no" to "extremely many", from "1" to "5"). In this study, the alpha coefficient of the scale was 0.82 .

\subsubsection{Design and procedure}

In this study, we used a 2 (trait power: high, low) $\times 2$ (money concept priming: Yes, no). The dependent variable is impulse purchase intention.

First, the subjects were asked to complete Sense of Power Scale, and the subjects were ranked from high to low. The top $27 \%$ were selected as the high trait power group, and the last $27 \%$ were the low trait power group.

In the money priming experiment, two groups of subjects were randomly assigned to the priming group with money concept and the priming group without money concept. They participated in the scrambled-words taskle test and completed the priming material task and the neutral material task respectively. Then, the subjects filled in a favorite sport to prevent them from guessing the purpose of the experiment. After completing the impulse purchase decisionmaking test, the subjects need to write down the decision-making reasons on the horizontal line. Finally, the subjects completed PANAS, at the end of the experiment, the participants expressed their gratitude to the subjects and presented a neutral pen as a gift. 


\subsection{Results and analysis}

\subsubsection{Effectiveness analysis of subject screening}

According to the score of the subjects on SPSS, 53 subjects with the top $27 \%$ score and 55 subjects with the lowest $27 \%$ score were selected from 198 subjects. Finally, 108 effective subjects were obtained. The average and standard deviation of the scores of the subjects with high trait power and low score are shown in Table 1. T-test was used to test the scores of the two groups. The results showed that there was a significant difference between the scores of high and low trait power, $\mathrm{t}(106)=18.69, \mathrm{p}<.001$, indicates that the grouping is valid.

Table 1 mean and standard deviation of the scores of subjects with high and low trait power $(\mathrm{m} \pm \mathrm{SD})$

\begin{tabular}{|l|l|l|l|}
\hline Group & $\mathrm{n}$ & $\mathrm{M}$ & $\mathrm{SD}$ \\
\hline High score group & 53 & 31.64 & 1.96 \\
\hline Low score group & 55 & 22.33 & 3.07 \\
\hline
\end{tabular}

2.2.2 The influence of trait power and money concept priming on impulse purchase intention

The average and standard deviation of impulse purchase intention in each group are shown in Table 2.

Table 2 Descriptive statistics of impulse purchase intention on trait power and money concept priming $(\mathrm{m} \pm \mathrm{SD})$

\begin{tabular}{|l|l|l|}
\hline & High trait power & Low trait power \\
\hline Prime with the concept of money & $11.31 \pm 4.15(\mathrm{n}=26)$ & $14.15 \pm 4.61(\mathrm{n}=27)$ \\
\hline Prime without the concept of money & $13.85 \pm 6.06(\mathrm{n}=27)$ & $12.82 \pm 3.52(\mathrm{n}=28)$ \\
\hline
\end{tabular}

In this study, the gender of the subjects was analyzed by independent sample t-test, the difference was not significant, $\mathrm{P}>0.05$, so the later analysis will not consider gender differences. Although low sense of power is not equal to negative emotion, it is related to emotion (Keltner et al., 2003), and emotion also affects impulse purchase intention (giner Sorolla, 2001). At the same time, personal disposable income is also the influencing factor of impulse purchase intention, so in order to analyze the research accurately, we need to control the variable emotion and disposable income.

Taking impulse purchase intention as dependent variables, trait power and money concept priming as independent variables, emotion and disposable income as covariates, a $2 \times 2$ covariance analysis was conducted. There is no interaction among emotion, disposable income and independent variables, ps $>.05$. Therefore, the slope homogeneity hypothesis can be established and covariance analysis can be carried out. The results of covariance analysis showed that the main effect of independent variable trait power was not significant $F(1,102)=1.86$, $p>.05$; the main effect of money concept priming is not significant $\mathrm{F}(1,102)=0.12, \mathrm{p}>.05$, the interaction between trait power and money concept priming is significant $\mathrm{F}(1,102)=4.06, \mathrm{p}<.05, \eta \mathrm{p}^{2}=.038$. The simple effect analysis showed that there was significant difference between the high and low trait power groups under the money concept priming group $\mathrm{F}(1,102)=5.57$,

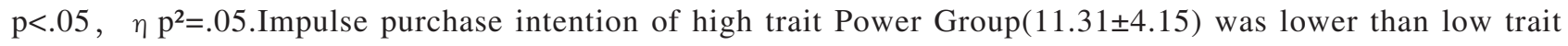
power group $(14.15 \pm 4.61), \mathrm{p}<.05$. There was no significant difference in the priming group without money concept $\mathrm{F}(1,102)=0.21, \mathrm{p}>.05$.

\subsection{Summary}

The results of this experiment show that: after the concept of money is activated, individuals with low trait power have higher impulse purchase intention than those with high trait power sense, and there is no difference in impulse purchase intention of individuals with high and low trait power when money concept is not activated.

\section{Experiment 2}

\subsection{Method}

\subsubsection{Subjects}

A total of 218 college students were randomly selected to take part in the trait power test. After ranking according to the total score, 117 subjects (58 boys and 59 girls) were selected to participate in the impulsive purchase decisionmaking experiment. The average age was 20 years old.

\subsubsection{Experimental tasks and materials}

(1) Sense of Power Scale (SPS) 
The same as experiment 1 .

(2) Amount of money priming task

Using Voh, Mead and Goode's (2006) reading materials and imaginative methods, the subjects were aroused about the psychological state of having different amount of money. The subjects in the money rich group were asked to read a short passage about the affluence of financial resources in their growing up years and imagine being in a situation of economic prosperity (Voh, et al., 2006; Sharma \& alter, 2012). The method of the money deficient group was the same as that of the rich group, and the reading content was money poor.

(3) Impulse buying decision test

The same as experiment 1 .

(4) Positive and Negative Affect Schedule (PANAS)

The same as experiment 1 .

\subsubsection{Design and procedure}

Two (trait power: high and low) $\times 2$ (money quantity priming: rich and poor) was used in the inter subject design. The dependent variable is impulse purchase intention.

In the money priming experiment, the subjects with high and low trait power were randomly assigned to money rich group and money deficient group. After reading the amount of money priming materials and imagination, the subjects were asked to describe the life they had just imagined with a few simple words on the horizontal line.

Others are the same as experiment 1 .

\subsection{Results and analysis}

\subsubsection{Effectiveness analysis of subject screening}

According to the score of the subjects on SPS, 57 subjects with the top $27 \%$ score and 60 subjects with the lowest $27 \%$ score were selected from 218 subjects. Finally, 117 effective subjects were obtained. The average and standard deviation of the scores of high trait power and low score groups are shown in Table 3. T-test was used to test the scores of the two groups. The results showed that there was a significant difference between the scores of high and low trait rights, $\mathrm{t}(115)=22.77, \mathrm{p}<.001$, indicates that the grouping is valid.

Table 3 mean and standard deviation of scores of subjects with high and low trait power $(\mathrm{m} \pm \mathrm{SD})$

\begin{tabular}{|l|l|l|l|}
\hline Group & $\mathrm{n}$ & $\mathrm{M}$ & $\mathrm{SD}$ \\
\hline High score group & 57 & 30.96 & 1.48 \\
\hline Low score group & 60 & 22.22 & 2.52 \\
\hline
\end{tabular}

3.2.2 The effect of trait power and money quantity priming on impulse purchase intention

The average and standard deviation of impulse purchase intention of each group are shown in Table 4.

Table 4 descriptive statistics of impulse purchase intention on trait power and money quantity priming $(\mathrm{m} \pm \mathrm{SD})$

\begin{tabular}{|l|l|l|}
\hline & High trait power & Low trait power \\
\hline Condition of money abundance & $12.64 \pm 3.49(\mathrm{n}=25)$ & $14.97 \pm 4.84(\mathrm{n}=30)$ \\
\hline Condition of lack of money & $10.91 \pm 4.14(\mathrm{n}=32)$ & $13.07 \pm 3.27(\mathrm{n}=30)$ \\
\hline
\end{tabular}

In this study, the gender was analyzed by independent sample t test, and the difference was not significant $(\mathrm{P}>0.05)$. Therefore, gender differences will not be considered in the later analysis. Because emotion and disposable income have influence on impulse purchase intention, experiment 2 also controls the two covariates of emotion and disposable income.

Taking impulse purchase intention as dependent variables, trait power and money quantity priming as independent variables, a $2 \times 2$ covariance analysis was conducted. There is no interaction between emotion, disposable income and independent variables, $p s>.05$. Therefore, the condition of covariance analysis is satisfied. The results of covariance analysis showed that the main effect of independent variable trait power was significant $F(1,111)=11.31, p<.01$, $\eta_{\mathrm{p}}{ }^{2}=.09$. Moreover, individuals with low trait power have higher impulse purchase intention than those with high trait power, and the main effect of money quantity priming is also significant $F(1,111)=6.71, p<.05, \quad \eta_{\mathrm{p}}^{2}=.06$. And the impulse purchase intention of individuals under the condition of money abundance is higher than that under the condition of lack of money. However, there was no significant interaction between trait power and money quantity 
priming $F(1,111)=0.01, p>.05$.

\subsection{Summary}

The results of this study show that both individuals with high trait power and low trait power have higher impulse purchase intention than those with money shortage.

\section{Comprehensive discussion}

Experiment 1 explored the effects of trait power and money priming on individual impulse purchase intention, and Experiment 2 explored the influence of trait power and money priming on individual impulse purchase intention. In Experiment 1, we found that under the condition of money priming, the impulsive purchase intention of high trait power subjects was lower than that of low trait power subjects; Experiment 2 further proved that the impulsive purchase intention of high trait power subjects was lower than that of low trait power subjects regardless of whether money initiated wealth or poverty. However, in Experiment 1, there was no difference in impulse purchase intention between high and low power people without money priming. In other words, the concept of money in the individual consciousness can make the subjects with high trait power become more rational and reduce their impulse purchase intention, which is consistent with previous studies. Tong, Zheng and Zhao (2013) confirmed that money concept priming can make college students pursue the safety and practicability of products for avoiding harm; meanwhile, psychological stereotype theory also believes that college students' utility or economic stereotype will be activated by money concept priming, with utility maximization as the goal orientation (Liu \& Aaker, 2008). In Experiment 2, we found that individuals with high trait power had lower impulsive buying tendency than those with low trait power, regardless of whether they were rich or short of money. According to the theory of social distance, college students with high sense of power are less dependent on others, more likely to perceive larger social distance, more abstract psychological representation and higher level of interpretation. Therefore, individuals with high sense of power are more likely to control impulse and delay gratification, so they will have less impulse buying behavior in the consumption process. However, the difference between high and low trait power is based on money priming, that is to say, money priming may induce college students' rational thinking, and then there are differences in interpretation level of subjects.

Experiment 2 also found that under the condition of rich money, college students' impulse purchase intention is higher than that under the condition of lack of money. It is likely that when college students are in a relatively simple environment, have a shallow understanding of money and have less disposable money, when facing a rich environment, their sense of control over the environment is enhanced, while their perception of risk is relatively weakened, so they are more likely to make impulsive purchase decisions; In the environment of lack of money, due to the lack of social resources and weak social viability of college students, individuals will have a higher risk perception, so the corresponding impulse purchase intention can be reduced. At the same time, compared with the poor priming, the rich priming provides an atmosphere and premise for college students to buy hedonism. Because college students have higher entertainment tendency, they are more likely to have impulse buying behavior.

This study further expands the influence of College Students' sense of power on impulse buying. Firstly, it extends the sense of state power to the sense of trait power; secondly, it finds that the potential sense of power of money influences the moderating variable of impulse purchase. Of course, there are also some shortcomings in this study, such as the lack of a comparison between the role of trait power and state power; in addition, impulse buying is distinguished by the choice of practical goods and hedonic goods in this study, and impulsive consumption can be defined from the perspective of commodity uniqueness in future research.

\section{Conclusion}

The main conclusions are as follows

(1) After priming the concept of money, whether rich or poor, students with low trait power have higher impulse purchase intention than those with high trait power, while there is no significant difference between high and low trait power groups in no money concept priming group. 
(2) No matter whether the level of college students' trait power is high or low, compared with the condition of lack of money, individuals have higher impulse purchase intention under the condition of rich money.

\section{Reference}

1. Duan Yi. (2014). Money enhances sense of control: from the perspective of social resource theory, master thesis of Hunan Normal University

2. Jiang Hongyan, Liu BANGSHUN, sun Peizhen. (2018). The influence of sense of power on consumer behavior and its theoretical explanation. Progress in psychological science, 26 (1), 1 - 13

3. Li Aimei, Luo Ying, Li Bin. (2016). "money priming" makes people rational or irrational? _ _ Money priming and consumer behavior decision. Foreign economics and management, 38 (6), 100-112

4. Wa Yu (2014). A study on the influence of online reviews on the purchase intention of consumers -- Based on the perspective of information communication, master's thesis of Zhejiang University

5. Yang Wenqi, Li Qiang, Guo Mingyang, fan Qian, he Yili. (2017). The influence of sense of power on individuals: the perspective of regulatory orientation. Acta psychologica Sinica, 49 (3), 404-415

6. Li linyao, Zhang Mian. (2013). Research on the formation mechanism of College Students' impulsive consumption -Based on the psychological perspective, modern business industry, 25 (6), 132-134

7. Anderson, C., John, O. P., \& Keltner, D. (2012). The personal sense of power. Journal of Personality, 80(2), $313-344$.

8. Fishbach, A., \& Dhar, R. (2005). Goals as Excuses or Guides: The Liberating Effect of Perceived Goal Progress on Choice. Journal of Consumer Research, 32(3), 370-377.

9. Baumeister, R. F., Bratslavsky, E., Muraven, M., \& Tice, D. M. (1998). Ego depletion: Is the active self a limited resource? Journal of Personality and Social Psychology, 74, 1252-1265.

10. Cutright, K. M., Bettman, J. R., \& Fitzsimons, G. J. (2013). Putting brands in their place: How a lack of control keeps brands contained. Journal of Marketing Research, 50(3), 365-377.

11. Rook, D. W., \& Fisher, R. J. (1995). Normative Influences on Impulsive Buying Behavior. Journal of Consumer Research, 22(3), 305-313.

12. Gal, D. (2012). A mouth-watering prospect: Salivation to material reward. Journal of Consumer Research, 38(6), 1022-1029.

13. Galinsky, A. D., Gmenfeld, D. H., \& Magee, J. C. (2003). From power to action. Journal of personality and social psychology, 85(3), 453-466.

14. Garbinsky, E. N., Klesse, A. K., \& Aaker, J. (2014). Money in the bank: Feeling powerful increases saving. Journal of Consumer Research, 41(3), 610-623.

15. Garbinsky, E. N., Klesse, A. K., \& Huang, S. (2016). The Power to know what you have: Feeling powerful increases money monitoring. Paper presented at the annual meeting of the Association for Consumer Research, Berlin.

16. Giner-Sorolla, R. (2001). Guilty pleasures and grim necessities: Affective attitudes in dilemmas of self-control. Journal of Personality and Social Psychology, 80, 206-221.

17. Gronmo, S. (1988). Compensatory consumer behavior: Elements of a critical sociology of consumption. The Sociology of Consumption, 65-85.

18. Guinote, A. (2007). Behaviour variability and the situatedfocus theory of power. European Review of Social Psychology, 18(1), 256-295.

19. Hansen, J., Kutzner, F., \& Wänke, M. (2013). Money and thinking: Reminders of money trigger abstract Construal and shape consumer judgments. Journal of Consumer Research, 39(6), 1154-1166.

20. Keltner, D. J., Gruenfeld, D. H., \& Anderson, C. (2003). Power, approach, and inhibition. Psychological Review, $110,265-284$.

21. Kim, J., Shin, Y., \& Lee, S. (2017). Built on stone or sand: The stable powerful are unethical, the unstable powerful are not. Journal of Business Ethics, 144(2), 437-447.

22. Liberman, N., Sagristano, M. D., \& Trope, Y. (2002). The effect of temporal distance on level of mental construal. Journal of Experimental Social Psychology, 38(6), 523-534. 
23. Liu, W., \& Aaker, J. (2008) . The happiness of giving: The time-ask effect. Journal of Consumer Research, 35(3), 543-557.

24. Abdolvand, M. A., Hanzaee, K. H., Rahnama, A., \& Khoshpanjeh, M. (2011). The effects of situational and individual factors on impulse buying. World Applied Sciences Journal, 13(9), 2108-2117.

25. McCullough, M. E., \& Willoughby, B. L. (2009). Religion,self-Regulation, and Self-Control: Associations, Explanations, and Implications. Psychological Bulletin, 135(1), 69-93.

26. Mogilner, C., \& Aaker, J. (2009). "The time vs. money effect": Shifting product attitudes and decisions through personal connection. Journal of Consumer Research, 36(2), 277-291.

27. Shukla, P., Banerjee, M., \& Adidam, P. T. (2013). The moderating influence of socio-demographic factors on the relationship between consumer psychographics and the attitude towards private label brands. Journal of Consumer Behaviour, 12(6), 423-435.

28. Rucker, D. D., \& Galinsky, A. D. (2008). Desire to acquire: Powerlessness and compensatory consumption. Journal of Consumer Research, 35(2), 257-267.

29. Rucker, D. D., Galinsky, A. D., \& Dubois, D. (2012). Power and consumer behavior: How power shapes who and what consumers value. Journal of Consumer Psychology, 22(3), 352-368.

30. Sharma, E., \& Alter, A. L. (2012) . Financial deprivation prompts consumers to seek scarce goods. Journal of Consumer Research, 39 (3) , 545-560.

31. Shiv, B., \& Fedorikhin, A. (1999). Heart and Mind in Conflict: The Interplay of Affect and Cognition in Consumer Decision Making. Journal of Consumer Research, 26(3), 278-292.

32. Smith, P. K., \& Trope, Y. (2006). You focus on the forest when you're in charge of the trees: Power priming and abstract information processing. Journal of Personality and Social Psychology, 90(4), 578-596.

33. Tian, K. T., Bearden, W. O., \& Hunter, G. L. (2001). Consumers' need for uniqueness: Scale development and valid ation. Journal of Consumer Research, 28(1), 50-66.

34. Tong, L., Zheng, Y., \& Zhao, P. (2013). Is money really the root of all evil? The impact of priming on consumer money choice. Marketing Letters, 24(2), 119-129.

35. Trope, Y., \& Liberman, N. (2003). Temporal construal. Psychological Review, 110(3), 403-421.

36. Dholakia, U. M. (2000). Temptation and resistance: An integrated model of consumption impulse formation and enactment. Psychology \& Marketing, 17(11), 955-982.

37. Van Dijke, M., \& Poppe, M. (2006). Striving for personal power as a basis for social power dynamics. European Journal of Social Psychology, 36(4), 537-556.

38. Vohs, K. D., \& Faber, R. J. (2007). Spent resources: Self-regulatory resource availability affects impulse buying. Journal of Consumer Research, 33(4), 537-547.

39. Vohs, K. D., Mead, N. L., \& Goode, M. R. (2006). The psychological consequences of money. Science, 314(5802), 1154-1156.

40. Zhou, R., \& Pham, M. T. (2004). Promotion and prevention across mental accounts: When financial prouduts dictate consumers \&investment goal. Jouranl of Consumer Research, 31(1), 125-135. 